\title{
Health Assistant Module
}

MARCEL SANCHEZ-PRIETO

Woodbury University

In recent years, the Public Office of Social Protection in Health from Baja California in México - REPSS - Regimen de Protección Social en Salud - has outgrown the capacity of its facilities, where in many cases clinical care and insurance offices are shared in a single module.

As in most cases of government projects, the emergence of the project mirrors the result of an urgent need to build an inexpensive facility that would be able to operate immediately. In the context of Tijuana, a city at the fringe with the US and with a large concentration of maquiladoras, the variable cost-time framed the container as the most viable alternative that allowed operating in less than three weeks.

The module functions as a prototype that can easily be reproduced and implemented in different municipalities, particularly in rural areas disconnected from urban centers. The industrial metal sheets of the container provide a canvas to texturize the facade in a way that is highly characteristic of traditional colonial architecture: the dual tone breaks the scale of the facade, framing the activity at the sidewalk. The intention of the module is to assist citizens to enroll in public health insurance and guide them to understand their rights and services provided by the public institution and their facilities in Baja California. The affordable module is originally situated next to the main Public General Hospital of Tijuana, providing guidance and support to the low-income population that is referred to the General Hospital.

\section{ADRIANA CUELLAR}

University of San Diego 

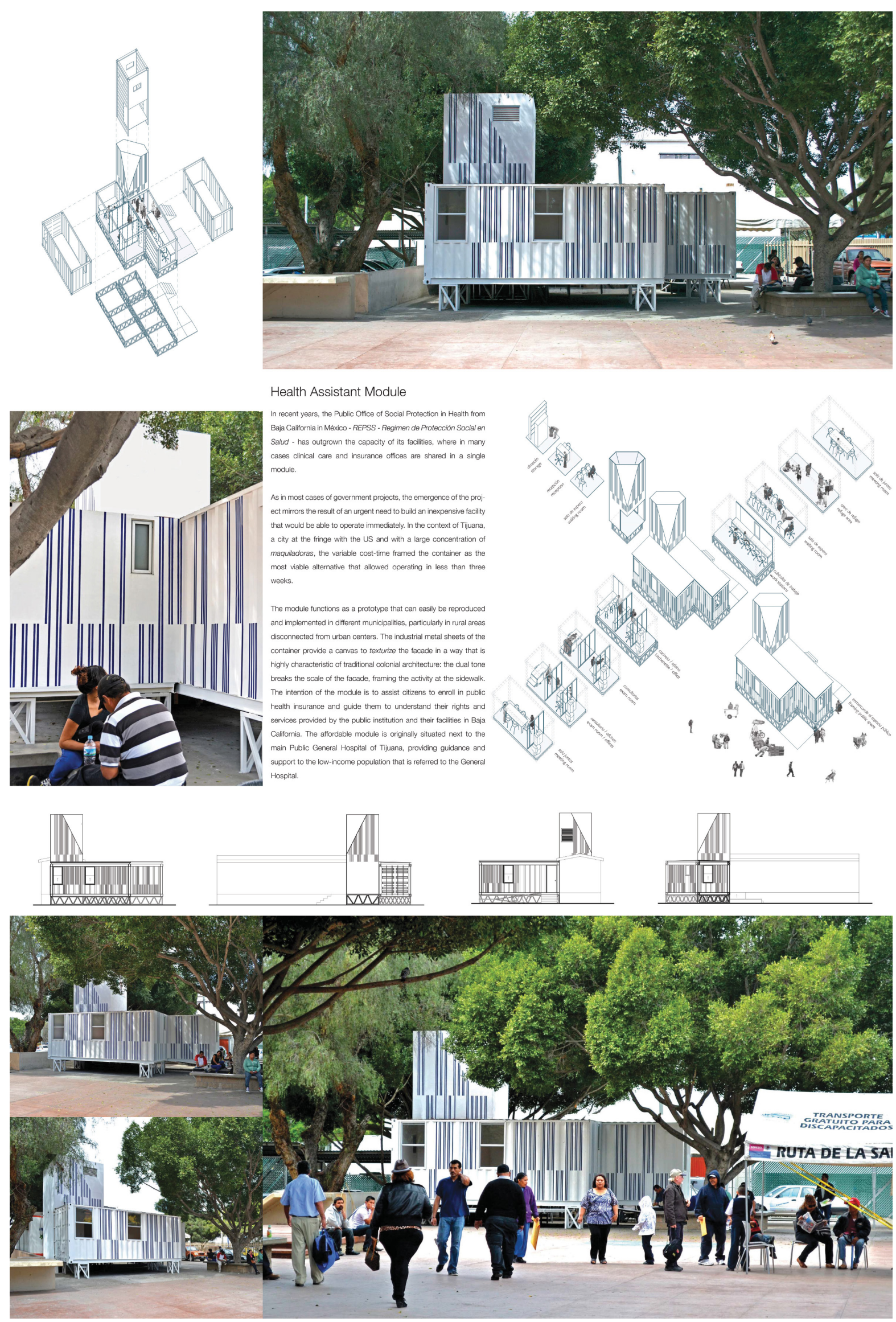